\title{
Samtalsmodell för bedömning och bemötande av suicidalitet hos personer som vårdas vid Statens Institutionsstyrelse
}

\author{
Av Eva da Silva och Lotta Scholander
}

ÅR 2004 tog en 16-årig pojke sitt liv på en av de institutioner där vi var verksamma som psykologer. Händelsen berörde oss djupt och vi har sedan dess drivits av övertygelsen att pojkens död inte ska ha skett förgäves. Utbildningar i suicidprevention, riktlinjer samt denna samtalsmodell är en följd av detta.

\section{Bakgrund}

Suicidalitet är ett samlingsbegrepp för att tänka på respektive genomföra självmordsförsök och självmord. I annan verksamhet yttrar den sig vanligen i livsleda eller mer eller mindre vaga tankar på att ta sitt liv. I vår verksamhet handlar det om oftast oväntade akuta suicidhot, suicidförsök och suicid. Bemötandet försvåras ofta av språksvårigheter.

Årligen görs ett antal allvarliga självmordsförsök bland de tvångsomhändertagna ungdomarna och klienterna. Tyvärr har även självmord förekommit. De personer som är satta att bedöma suicidrisk inom Statens Institutsstyrelse är psykologer, som ibland inte tidigare träffat ungdomen/klienten. De står således för svåra utmaningar.

Ett arbete med riktlinjer och utbildning för all behandlingspersonal inom myndigheten genomfördes 2010 (SiS 2015). Målsättningen var att alla skulle ha kunskap om självmordsprevention; att vara uppmärk- sam på signaler, att bemöta personen relevant och att hantera kriser som uppstår i samband med suicidalt beteende.

Nästa fokus för oss var att erbjuda kompetensutveckling för de psykologer som skulle ansvara för utbildningar i suicidprevention på institutionerna, samt ytterst vara ansvariga för suicidbedömningar och för behandling. Suicidprevention i Väst (SPIV) har sedan dess årligen erbjudit psykologerna en fem dagar lång specialistgrundande utbildning i suicidalitet med professor Jan Beskow som ansvarig. Erfarenheter

Statens Institutionsstyrelse (SiS), är huvudman för de institutioner som bedriver individuellt anpassad tvångsvård i Sverige för ungdomar med allvarliga psykosociala problem och vuxna med missbruksproblem. Uppdraget är att ge klienter bättre förutsättningar för ett socialt fungerande liv utan missbruk och kriminalitet.

SiS förfogar över ca 700 platser för ungdomsvård och 400 platser för missbruksvård.

Ca 3500 personer är anställda på institutionerna. 
från dessa utbildningar har vi nu sammanfattat i en samtalsmodell som blev färdigställd 2017 och som nu redovisas här.

\section{Riskbedömning}

\section{Självmord}

Att förutse och därefter förebygga individuella våldshandlingar är svårt av rent statistiska skäl. Det gäller såväl dödande våld mot andra, t ex dråp, som mot personen själv. Detta är nämligen relativt sällsynta handlingar med komplexa orsaker. Ty även om antalet självmord i Sverige sammantaget är oacceptabelt högt, ca. 1.500 per år, är det bara i genomsnitt 18 av 100 ooo människor 15 år och äldre som tar sitt liv under samma år. De mest använda skalorna för att predicera självmord har därför visat sig otillförlitliga (SBU 2015).

\section{Självmordsförsök}

Många använda riskfaktorer kan ha funnits under åratal, t ex depression. Det ger höga risksiffror men låg prediktionsförmåga. Då är det bättre att söka efter faktorer som omedelbart föregår ett självmordsförsök, t ex akuta påfrestningar, förtvivlan och förvirring. Letandet efter sådana faktorer har nu förfinats till att omfatta även små knappt märkbara utlösande triggers och därefter utveckla personens egna kopingstrategier
(Michel oa 2011 och 2015). Mätt i återfall i suicidförsök har denna metod, Attempted Suicide Short Intervention Program, ASSIP, givit förvånande gott resultat (GysinMaillart oa 2016). Studien behöver dock reproduceras.

\section{Tänka på suicid}

Det starka fokuset på självmord har giort att man vanligen inte skiljer mellan tankar och handlingar utan sammanför dem under det breda begreppet suicidalitet. Av 400 personer som anger att de tänker på suicid, är det bara en som tar sitt liv samma år (FORTE 2015). Att tänka på självmord är därför vanligen inte farligt utan ett led i en problemlösning. Man kan då behöva stöd av någon som nyfiket utforskar och tillsammans finna alternativ samt hopp.

\section{Samtalsmodell}

Denna samtalsmodell kompletterar och integrerar nya landvinningar med SiS riktlinjer. Bedömningen av självmordsrisk innefattar eller följs direkt av terapeutiska moment. Detta är viktigt för att sänka risken för suicid. Vår modell har tagit sin grundform utifrån kognitiv psykoterapi (Beck 1972, Wenzel 2005, Ellis 2006), kommunikationens neurobiologi (Siegel 1990 och 2012, Porges 2011) samt traumakunskap (van der Kolk 2015). Metodiskt liknar den ASSIP vad gäller fokus på 
akut suicidalitet, detaljbeskrivningar av korta sekvenser före och under den suicidala episoden samt försök att fånga triggers och utveckla personens egna kopingstrategier. Däremot har samtalen inte videofilmats. Anpassningar har också skett till de specifika målgrupperna, att arbetet sker i slutenvård samt den vanligen korta behandlingstiden.

Samtalsmodellen innefattar ett ramverk av fyra samtal med skilda fokus och en samling av valbara metoder och förhållningssätt att använda flexibelt beroende på situation och behov. Suicidriskbedömning görs vid första samtalet men följs upp kontinuerligt under de följande samtalen.

Samtalen ska initieras och utföras under kort tid efter den akuta suicidala episoden. Flera samtal i veckan kan behövas. Det rekommenderade innehållet kan behöva spridas över flera samtal. Varje samtal kan utföras över flera tillfällen.

Vi har valt uttrycket akut suicidal episod för att inte begränsa utövarens insatser till ett redan genomfört suicidförsök utan även fånga upp tidiga tecken på förändrat stämningsläge. Fler anledningar att starta en samtalsserie är tex. att personen just har återkommit från psykiatrin efter ett försök, att psykolog eller annan på institutionen uppfattar oro för suicidalitet eller att personen själv har berättat om suicidtankar. Många ungdomar och klienter på SiS uppvisar inte de mer «traditionella» tecknen på suicidalitet (Berman 2011, Björkenstam 2011., Gustafsson oa 2016). Istället uppvisar de annat riskfyllt, livshotande beteende, ofta med inställningen «dör jag så dör jag», som om det inte uppmärksammas kan leda till döden. I våra målgrupper kan det ofta vara svårt, eller rent av omöjligt, att avgöra enbart utifrån beteendet i sig om det är suicidförsök eller självskadebeteende.

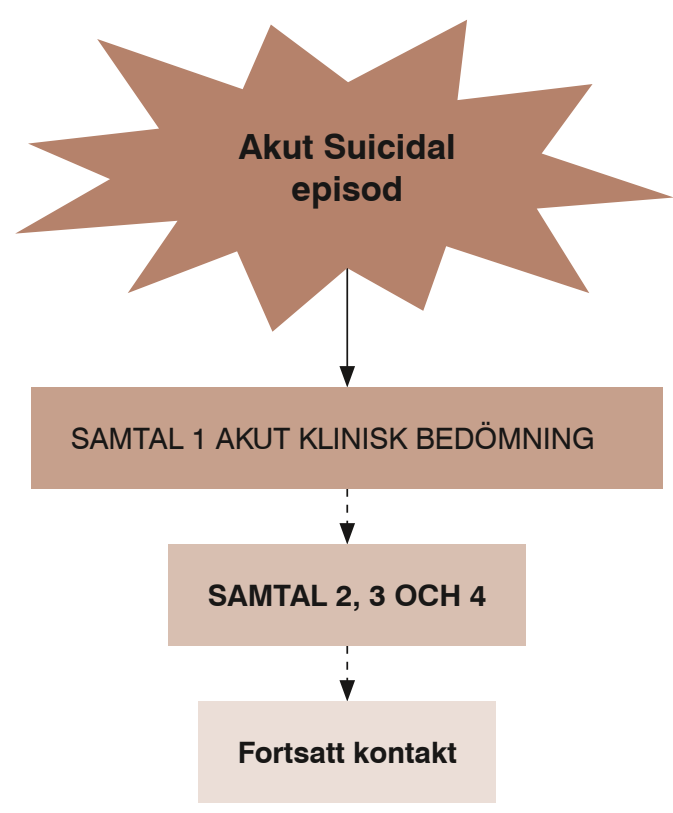

Särskilda faktorer hos målgruppen som ökar risk för suicid:

- beteenden under samtalet såsom att avsäga sig hjälp, ge ofullständig rapportering, ambivalens och avsaknad av engagemang.

- Kvinnor och män som i ungdomen dömts för kriminalitet har förhöjd suicidrisk.

- Upplevelser av mental smärta ökar risk.

- Aggressivitet och impulsivitet gör riskbedömningen något mindre förutsägbar.

\section{Samtal 1: Narrativet och suicidriskbedömningen}

Fokus i första samtalet är att rädda liv genom att:

- Bedöma suicidrisk för de närmaste timmarna och dygnet

- Minska suicidalitet genom att skapa en behandlingsallians

Det är svårt och ibland rent av omöjligt att skapa en terapeutisk allians redan vid första mötet med en suicidal person (Horvath oa 2006, Jobes 2006). Ofta bär ungdomarna och klinterna på erfarenheter av komplexa trauman. Att skapa allians genom förhållningssätt som ökar en känsla av säkerhet och trygghet är centralt. Detta är den första behandlingsinterventionen för att påverka den akuta suicidaliteten. Inte sällan är detta så långt som psykologen kommer innan personen kan berätta om sin situation. Det innebär att «samtal 1», kan bli många träffar med stabilisering och trygghet som mål.

Ett självmordsförsök behöver förstås som ett agerande som har betydelse utifrån individens livserfarenheter och som kan berättas som en historia, ett narrativ, för en uppmärksam lyssnare, i vilken vi ger mening till händelser i syfte att beskriva de egna erfarenheterna. Mening skapas genom att sätta in/tolka händelserna i ett speciellt sammanhang, tex. i form av scheman och livsregler.

Fortsatt fokus är att försöka få ihop personens berättelse, oftast från timmarna före den suicidala händelsen fram till denna stund och att försöka förstå vad som kan utlösa nya suicidala episoder. För någon individ är berättelsen som leder till suicidhandlingen snabb och impulsiv, för andra kan berättelsen handla om en livslång kamp. Psykologen behöver aktivt lyssna efter idiosynkratiska mönster och akuta triggers, utan att tränga sig på med snabba lösningsförsök: «lag vill gärna höra vad som ledde dig till att försöka/vilja avsluta ditt liv.»

Det är viktigt att ungdomen/klienten redan vid första samtalet får med sig något som kan inge hopp, tex. en kopingstrategi, andningsteknik eller åtminstone en tidpunkt att hålla fast vid för nästa möte: «jag kommer hit igen om 1 timme, försök till dess att ...» 
Det finns inga genvägar i bedömningen av individuell risk för självmordshandling. Det är bedömaren, som med sin allmänna kliniska kunskap, med sin specifika kunskap i suicidalitet och med sin förmåga att närma sig den suicidala ungdomen eller klienten, kommer fram till en individuell prognos eller risk för (ny) självmordshandling. Utöver att bedöma risk är det viktigt att även uppmärksamma personliga styrkor som skyddar (tex. kapacitet att gå in i en terapeutisk allians, att personen lyfter fram egna styrkor, att tidigare livskriser har hanterats, att socialt stöd finns, motivation att medverka i behandlingsplanen). Efter Samtal 1 och efter alla följande samtal sker implementering och kommunikation av suicidriskbedömningen: Psykologen formulerar behov av tillsyn och bemötande för hantering av den akuta situationen, kommunicerar med övrig personal samt dokumenterar fortsatt hantering

\section{Samtal 2: Exponering med problemlösning}

Psykologen och ungdomen/klienten går igenom vad som berättats och bearbetats i samtal 1. Vad var hjälpsamt? Samtal om den suicidala episoden kan dessutom sätta igång upplevelser som om ursprungshändelsen upprepas, som måste fångas upp. Detta kan medföra triggning av ett "suicidal mode» (Wenzel 2009). Med detta menas en tidigare utvecklad kognitivt, emotionellt och beteendemässigt färdig suicidplan. Beroende på individens förmåga att reflektera och stå ut med ångest kan exponeringen ha en behandlande effekt. Hen får då möjlighet att upptäcka alternativ problemlösning. Till exempel genom frågorna «Hur är det nu jämfört med förra gången?», «Förra gången berättade du................, hur tänker du nu?» Tillsammans formulerar behandlare och klient strategier som är behïlpliga här och nu!

\section{Samtal 3: Medvetenhet om mönster och krisplan}

Erfarenheter och lärdomar från samtal 1 och 2 gås igenom - vad var hjälpsamt? Hur är det idag jämfört med förra gången? Nu finns mer erfarenheter och kunskap som kan formuleras i mönster som leder till suicidal kris. Behandlaren och ungdomen/klienten formulerar och vidareutvecklar de strategier som varit behiälpliga. En krisplan formuleras gemensamt.

\section{Samtal 4: Långsiktiga mål och säkerhetsplanering}

Säkerhetsplanering och mål för längre tid påbörjas. Användning av psykoedukativa verktyg (kan även göras tidigare) och involvering av nätverk blir viktiga verktyg. Fortsatt kontakt rekommenderas efter samtal 4 .

\section{Valbara metoder}

Modellen innefattar ett antal valbara metoder fördelade i kategorierna; A. Bedömningsinventorier, B. Kognitiv teori och C. Anknytnings- och traumateori. Metoderna kan användas separat eller i olika kombinationer beroende på problematik och behov hos den enskilde ungdomen eller klienten. Några av metoderna kan användas i syfte att utföra en bedömning och andra i syfte att förse klienten med fungerande verktyg för att hantera sin egen suicidalitet. Kliniska självmordsriskbedömningar är bland det svåraste psykologen kan utföra i sin profession och det är inte alltid helt enkelt att komma fram till en stringent ståndpunkt. En hiälp kan då vara en kollega som ger en second opinion.

I dokumentet för samtalsmodellen finns bilagor med ytterligare material som kan vara till god hjälp vid bedömning och behandling; arbetsblad för bedömning och behandling kopplade till teorin bakom förhållningssättet och ett psykoedukativt dokument som kan användas i samtal med ungdom/klient i syfte att normalisera och kommunicera suicidalitet samt riktlinjer för kontakt med familj och närverk. Sådana kontakter ska planeras inom ramen för en individuell bedömning. I de flesta fall kan ungdomen eller klienten själv avgöra vem som är närstående. «Jag måste ringa en av dina närstående. Vem vill du att jag ska ringa»?

\section{A. Bedömningsinventorier}

SiS-modellen innehåller tre inventorier som kan vara ett stöd i den kliniska självmordsriskbedömningen. Suicidstegen avser att beskriva den suicidala processen från nedstämdhet/hopplöshet till aktiva planer. Den strukturerade siälvmordsriskbedömningen innefattar en mall för klinisk intervju med ungdomen eller klienten och värdering av risk för självmordshandling samt ett dokument för planering av tillsyn och bemötande. Det tredie inventoriet Suicide Status Form, SSF-III, är ursprungligen tänkt att användas av patienter

\section{A. Bedömningsinventorier}

1. Suicidstegen

2. Strukturerad bedömning avseende akut självmordsrisk

3. Suicide Status Form, SSF-III

\section{B. Kognitiv teori}

1. Två forskare

2. 5-faktormodell

3. Tankestrategier

4. Precisionssamtal problemlösning

\section{Anknytnings- och traumateori}

1. Aktiveringsmodellen

2. Klinisk allians

3. Narrativa samtal

4. Dissociation

5. Icke-verbal kommunikation

6. Impulsivitet

7. Reviravstånd 
tillsammans med sina behandlare. Bedömaren inom SiS kan också själv använda struktur och innehåll från formuläret i syfte att underlätta sitt bedömningssamtal.

\section{B. Kognitiv terapi}

Två forskare, 5-faktormodellen, kognitiv omstrukturering och tankestrategier är metoder som används i kognitiv terapi (Beck 1972). Två forskare (Beskow 2013), innebär att klienten och psykologen gemensamt utforskar en problemsituation, där ingendera parten har tolkningsföreträde. Istället försöker man på ett öppet sätt att se hur det «kunde bli så här». Samtalet syftar till att identifiera särskilt svåra händelser där suicidhandlingen inte är en obegriplig händelse i ett perfekt system utan fullt begriplig i ett dysfunktionellt system. Metoden används också inom ramen för ASSIP.

5-faktormodellen lanserades av Christine Padesky (Padesky 1990). Det är ett analytiskt verktyg för att kunna hejda, fånga in och beskriva mikrosituationer. En mikrosituation är det som händer under ett ögonblick, som del i ett flöde av ögonblick (Stern 2005). Att förstå inre snabbas skeenden är till god hiälp för att själv förstå och kunna hantera sin suicidalitet.

5-faktormodellen omfattar fem olika delar av en upplevelse, alla i interaktion med varandra. Samtliga finns på såväl icke-medveten som medveten nivå. Den sociala ringen «omgivning» omsluter de fyra personliga ringarna kognition, känsla, kropp och beteende. Se figur:

\section{Omgivning/Situation/Sammanhang}

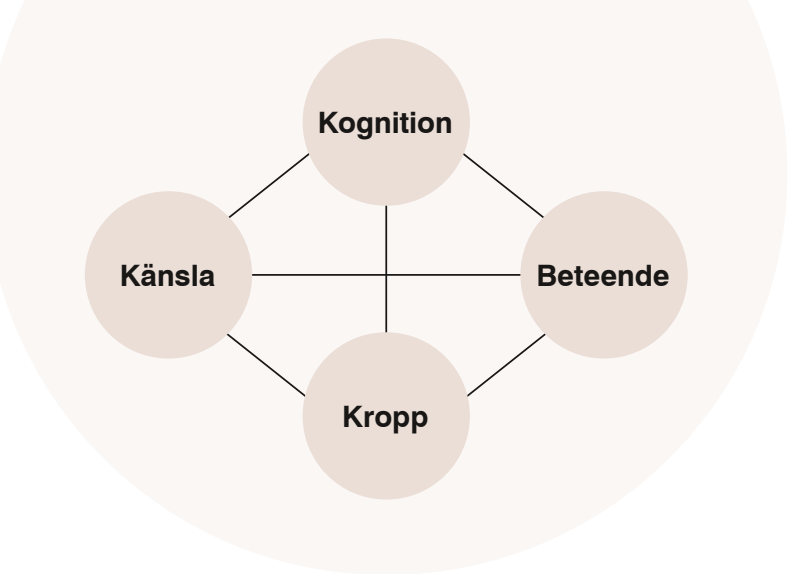

- Kognitioner: varseblivning, bild, tanke, minne, plan

- Känsla: primär, sekundär

- Kroppsreaktioner: aktivering, avspänning

- Beteende: kroppsspråk, handling, ord
Kognitiv omstrukturering och tankestrategier. Kognitioner är centrala för att skapa förståelse, bearbeta och nå fram till ett slutligt handlingsalternativ. Kognitiv omstrukturering är förmågan att kunna se en känslomässig upplevelse på ett nytt sätt, att växla perspektiv. Tankestrategier är olika sätt att bearbeta och förstå intryck. Ett 30-tal olika sådana strategier har beskrivits, varav några lyfts fram i vår modell. Exempel är «negativ selektiv perception», att vanemässigt fastna för det negativa i flöden av inkommande intryck.

«Katastroftankar» innebär att låta sådana negativa intryck förstoras och sluta i total katastrof, vilket leder till ökad ångest.

Precisionssamtal/Problemlösning innebär att koncentrera sig på den brist i problemlösningsförmåga som lett fram till de akuta tankarna att döda sig själv. Genom respektfullt utforskande av den suicidala episoden, att kartlägga kontext och triggers och att följa suicidaliteten bakifrån och hur den utvecklats mot det som just nu gör det omöjligt för ungdomen eller klienten att leva vidare, kan mönster av försök till problemlösning framträda. Problemlösning kan ske på två sätt: funktionell problemlösning eller dysfunktionell problemlösning. Det är den senare som ligger bakom den akuta suicidala situationen.

\section{Anknytnings- och traumateori}

Människans aktiverings- eller arousalsystem är organiserat på tre nivåer. Aktivering er den centrala funktionen bakom varje känsla och bör uppmärksammas terapeutiskt. I mitten finns det funktionella fältet, toleransfönstret. När sympatiska nervsystemet är aktiverat och särskilt när man är pressad eller trött, hamnar man lätt i ett tillstånd av hyperarousal. Personen kan inte kognitivt hålla ihop situationen och kan ytterst hamna i dissociation. Ilskeutbrott är ett tecken på att individen är i stress, i hyperaktivitet. Låg impulskontroll och ilska korrelerar med självmordsbeteende. Avsaknad av planering kring självmord innebär inte minskad risk hos en person med mycket impulsivitet. Dessa uttrycker en lägre grad av medvetenhet och reflektion kring sitt försök: «Jag tappade kontrollen bara, vet inte varför». Personer med impulsivitet och aggressivitet är extra känsliga för livsstressorer och problem. De reagerar gärna med ökad ångest och ilska inför det, vilket sedan kan övergå till suicidalt tänkande.

Toleransfönstret - en bild av generell aktivering, arousal (Ogden 2006) förenklad av författarna.

Hyperarousal

Fight/Flight

Toleransfönster/Funktionell arousal

Safety

Hypoarousal

Freeze 
När parasympatiska nervsystemet sänker aktivitetsnivån kan tillvaron också närma sig en dissociationsliknande form. Personen «stänger av» och blir svår att nå fram till. Vid svåra trauman kvarstår dissociationerna. Att göra ett suicidförsök är en traumatisk erfarenhet i en människas liv, som inte sällan föregåtts av andra tidigare trauman.

Psykologen behöver varsamt leda ungdomen/ klienten tillbaka till en känsla av trygghet, till sitt toleransfönster. Då kan mänsklig närvaro, tystnad, kanske en filt vara mer verksamt än språkliga kommunikationsförsök. Reviravstånd avser känslighet för lämpligt avstånd, kroppsspråk och mimik. Det visar sig att om en terapeutisk relation som präglas av tillit tidigt infinner sig är risken för ny suicidal handling mindre än om en allians inte föreligger.

\section{Slutord}

SiS psykologer har efterfrågat en konkret modell som hjälp i det svåra arbete suicidbedömning och behandling av suicidnära personer innebär. Denna modell ska kunna fungera som ett sådant stöd i arbetet. Ett 2o-tal psykologer har redan fått modellen presenterad under sin suicidpreventions-utbildning under våren 2017 och givit synpunkter på den. Våra intentioner är att modellen ska kunna rädda liv men även garantera att ungdomar och klienter kan få ett gott omhändertagande med ett korrekt bemötande. Psykolog Kristin Wahnström har använt modellen i sitt arbete på ett av SiS ungdomshem med en suicidnära ungdom och hon presenterar sina erfarenheter i en fallbeskrivning i anslutning till denna artikel.

Tidigare publicerat i SOKRATEN nr. 42017.

\section{REFERENSER}

Beck, Aaron T. (1972). Depression; Causes and Treatment. Philadelphia: University of Pennsylvania Press.

Berman, A.L., Jobes, A.D., Silverman, M. M., (2011). Adolescent Suicide. Assessment and Intervention. Washington DC: American Psychological Association.

Beskow, I., Palm Beskow, A., Ehnvall A. (2013). Suicidalitet som problemlösning, olyckshändelse och trauma. Lund: Studentlitteratur AB.

Björkenstam E. et al. (2011). Iuvenile delinquency, social background and suicide-a Swedish national cohort study of 992881 young adults. Int I Epidemiol, 40, 6, 1585-1592.

Ellis TE (ed). (2006). Cognition and Suicide. Theory, Research and Therapy. Washington: American Psychological Association.

Freeman, A., DeWolf, R. (2008). De 10 dummaste misstagen klyftiga personer gör. Stockholm: Natur och Kultur.

FORTE. (2015). Problemet siälvmord. Stockholm: Forte.

Gustafsson, L. H., Lindberg, T. (2016). Möta barn på flykt. Enkel handbok för alla. Stockholm: Unicef.

Gysin-Maillart, A., Schwab, S., Soravia, L., Megert, M., Michel, K. (2016). A Novel Brief Therapy for Patients Who Attempt Suicide: A 24-months Follow-Up Randomized Controlled Study of the Attempted Suicide Short Intervention Program (ASSIP). PLOS Medicine, DOI:10.1371/iournal.pmed.1001968 March 1
Horvath, A. O., Symonds, B., D. (1991). Relation between working alliance and outcome of psychotherapy: A meta-analysis. Journal of Counceling Psychology, 38, 139-149.

Jobes, D. (2006). Managing Suicidal Risk. A Collaborative Approach. New York, NY: Guilford Press

Kuyken, W., Padesky, C.A. \& Dudley, R. (2009). Collaborative Case-Conceptualization. Working Effectively with Clients in Cognitive-Behavioural Therapy. New York: Guilford Press.

Michel, K., Jobes, D. (2011). Building a Therapeutic Alliance with the Suicidal Patient. Washington DC: American Psychological Association.

Michel, K., Gysin-Maillart. A. (2015). ASSIP. Attempted Suicide Short intervention program. Boston, MA: Hogrefe Publishing.

Ogden, P., Minton, K., and Pain, C. (2006). Trauma and the body: A sensorimotor approach to psychotherapy. New York: Norton

Porges, S.W., (2011). The polyvagal Theory: Neurophysiological Foundations of Emotions, Attachment, Comminication, and Self-regulation. New York: WW Norton

Siegel, D.I. (1999). The developing mind: How relationships and the brain interact to shape who we are. New York; Guilford Press.

Siegel D.I. (2012). Pocket guide to interpersonal neurobiology. An integrative handbook of the mind. New York: W.W.Norton \& Co.

SiS, Statens institutionsstyrelse (2015). SiS riktlinjer för självmordsprevention och hantering av allvarliga självmordsförsök och självmord. Stockholm: Statens institutionsstyrelse.

SBU. Statens beredning för medicinsk och social utvärdering (2015). Instrument för bedömning av suicidrisk. En systematisk litteraturöversikt.

Van der Kolk, B. (2015). The Body keeps the Score. Brain, mind and body in the healing of trauma. Great Britain: Penguin Books.

Ogden P, Minton K, Pain C. (2006). Trauma and the Body. A Sensorimotor Approach to Psychothearpy. London: Norton o Co.

Mooney K.A. \& Padesky C.A. (1990). Clinical tip: Presenting the cognitive model to clients. International Cognitive Therapy Newsletter 1990:6,13-14.

Stern D. (2005). Ögonblickets psykologi. Om tid och förändring i psykoterapi och vardagsliv. Stockholm: Natur och Kultur. Eng. Stern D. (2004). The present moment in psychotherapy and everyday life. Norton series on interpersonal neurobiology.

Wenzel A, Brown GK, Beck AT. (2009). Cognitive Therapy for Suicida Patients. Scientific and Clinical Applications. Washington: American Psychological Association.

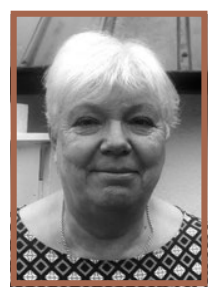

EVA DA SILVA, leg psykolog, specialist i klinisk psykologi, leg psykoterapeut KBT.

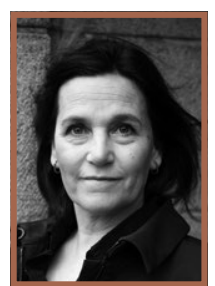

LOTTA SCHOLANDER, leg psykolog, leg psykoterapeut KBT, handledare KBT. 